\title{
Methodological Problems of Ethno-Cultural Studies
}

\author{
Sahipzhamal Askarovna Uzakbayeva ${ }^{1} \&$ Altynai Abdihanovna Beisembayeva ${ }^{1}$ \\ ${ }^{1}$ Kazakh University of International Relations and World Languages named after Ablai khan, Almaty, \\ Kazakhstan
}

Correspondence: Sahipzhamal Askarovna Uzakbayeva, Muratbaeva str., 200, Almaty, 020000, Kazakhstan. E-mail: zhanat_2006@mail.ru

$\begin{array}{lc}\text { Received: February 28, } 2015 & \text { Accepted: March 20, } 2015 \quad \text { Online Published: April 26, } 2015 \\ \text { doi:10.5539/res.v7n6p249 } & \text { URL: http://dx.doi.org/10.5539/res.v7n6p249 }\end{array}$

\begin{abstract}
In science unsettled certain approaches to the study of various problems. In recent decades, firmly become apparent methodological orientations such as comparative studies, which became one of the leading methodologies humanities throughout the scientific CIS, including in Kazakhstan. There is a need in the methodology of integrative, synthetic nature as a methodological function can only perform cultural studies approach, which includes two aspects of the study of cultural phenomena: the cultural and logical. Cultural approach in itself already suggests the breadth of coverage of the material and arguments, breadth of vision scientist and justified it by the fact that it is based on a wide knowledge of the culture of both the world and his nationality (Taylor, 1989). Logical approach clearly requires compliance with sound, the sequential method of reasoning. The unity of these two approaches involves the scientific base and integrally covers the complexity of cultural phenomena and relationships.
\end{abstract}

Keywords: methodology of ethno-cultural studies, comparative studies, culture ethno cultural studies approach, semiotic approach, national culture, social culture

\section{Introduction}

To date, the science is quite unsettled certain approaches to the study of various problems. Strongly indicate the directions in which research continues global scientific theories. Such methodological orientations as comparative studies only recently have caused sharp attacks; have become recognized throughout the scientific CIS. Comparative Kazakhstan has become one of the leading methodologies humanities.

However, the current socio-cultural situation requires specialist broader and democratic approach to research in various fields of science, expanding horizons, and the ability to navigate in complex, ambiguous and contradictory processes taking place in the world of science at different scales. Earth has become particularly strong today - come into contact phenomena, especially the former strongly localized in space and time. One of the priorities of scientific thought has been the study of human consciousness. Here it is appropriate to recall two approaches to human: in Russian culture, expressed M. V. Lomonosov, and Kazakh culture, expressed in Kazakh folk wisdom - the proverb. Wide field of human perception of Mikhail Lomonosov called "far man," a man and Kazakhs were evaluated as "all species." And in fact, other definitions can be seen sense ideas about man wise, have a wide field of knowledge, great experience (Rojek, 2000).

\section{Method}

The need for a different approach is a broader; more volume is to the study of cultural phenomena become apparent and urgent. There is a need in the methodology of integrative, synthetic nature. In our view, such a methodological function can only perform cultural studies approach.

This term includes two aspects of the study of cultural phenomena: the cultural and logical. Cultural approach in itself already suggests the breadth of coverage of the material and arguments, breadth of vision scientist. Cultural approach is justified by the fact that it is based on a wide knowledge of the culture of both the world and his nationality. However, disclosure of the essence of cultural phenomena is impossible without the inclusion of the logical aspect. Logical approach clearly requires compliance with sound, the sequential method of reasoning. A distinctive feature of inference is that from true premises it always leads to a true conclusion (Benoist, 1998). This explains the great interest that logic shows to the right conclusions. They allow of already existing knowledge to learn new knowledge and, moreover, with the help of "pure reasoning", without any appeal to 
experience, intuition, etc. Correct reasoning like reverses and specifies our knowledge. It gives an absolute guarantee of success, rather than simply providing one or another - perhaps even higher-the probability of a true conclusion. Logic reveals the meaning and expression of various cultural phenomena, a different relationship between the concepts, definitions of probabilistic and statistical reasoning, sophistry and paradoxes, etc. However, all this is subject to the decision of the main tasks of logic is correct reasoning. Only solution to this problem allows us to formulate the problem in a logical method for the study of cultural phenomena to truth. In conclusion, the logical approach follows from the premises by logical necessity, and the general scheme of such an argument is with a logical law. Some tautology this definition explains the specifics of formal logic as a science, according to which "any way to describe the logical form contains a specific hypothesis about its structure" (Gilbert, 2008).

Become customary to take second part of the name of Science- "logy" to mean "the word." However, this is a misconception. It should be noted that the word "logos", the underlying definition of most sciences, involves a logical approach to their study. The Greek word "logos" means "to", "organize". As we see in the word "logos" is reflected intellectually is analytical activities mind apprehends orderliness, consistency and harmony of the world (Bakhtin, 1981)

Heraclitus even coined the term "logos" in philosophical language to refer to some universal law, primordial being, acts as a guarantor of ordering the world, its conformity to law for all dynamic and catastrophic processes occurring there. Gradually understanding of the category "logos" begins to transform. First historians "logos" was perceived as a "world mind", which controlled nature and man. Then "logos" became identified with the "Word of the living God" and was personified as the substantial identity of the Son of God. And it is the Judeo-Christian tradition adopted the perception of a "logos" as "word" (Toynbee, 1991).

Understanding the culture and science of culture is different. There are many definitions of culture, depending on the approach to its study. Thus, the understanding of culture as "the cultivation, education, education and development" from "colo, colere"-nurture, cultivate the land to farm. This is one of the concepts that have long been regularly used by historians. Different understanding of culture is a key category of all anthropological disciplines in the West, historical and cultural in Russia. Gorgeous evaluation culture was given by Jean-Paul Sartre: "Culture of nothing and no one makes, and is not justified. But it is the creation of man: he projects into it recognizes in itself; only in this critical mirror he sees his appearance (Sartre, 1996). Sartre's definition is purely Western spirit. Much closer to understanding the Asian culture is cultural studies of perception as "the service of understanding" on the figurative definition of S. V. Savchenko.

We are based on an understanding of culture as a system of knowledge, a complex and multi-level system that selects and reflects the contradictions of the world" (Savchenko, 2000).

Cultural born at the junction of many different disciplines: philosophy, psychology, religious studies, history, art history, political science, semiotics, ecology, history of science, etc. The diversity of sciences gave rise to cultural studies, and especially the study of science, together and created one of its cognitive natures, which provides the possibility of awareness of cultural approach as a basic principle of the methodology of many sciences today. Nowadays, in many studies in the humanities, there is a subconscious desire for cultural approaches, particularly in the works on pedagogy, psychology, history, etc. Particularly, it is acute need for such an approach to the study of the Kazakh culture (Nietzsche, 1990).

Kazakh culture is a complex phenomenon and laminated. Not coincidentally, the study of the phenomena of the Kazakh culture is most often used semasiological method requiring the study of culture as a sign system. As is known, the semiotic methodology typical allocation of three levels of study sign systems: Syntactics, semantics and pragmatics. Syntactic structure studies of combinations of signs and rules of their education, regardless of their values and functions of symbolic systems. Semantics studies sign systems as a means of expression of meaning in terms of the interpretation of signs and sign combination. Pragmatics studies the relationship between sign systems and those who perceive interpret and use the information in these posts (Uzakbaeva, 1998).

Founder of semiotics American logician Charles Pierce gave a typology of signs, explored the functioning of signs, and questioned the value of the figure showed triadic nature of the sign, which later found its embodiment in three levels of semiotic analysis (syntactics, semantics and pragmatics). Charles S. Peirce also identified three bases as the iconic sign in his classification of signs, index and symbol. Charles S. Peirce ideas have continued to work Ch. Moris, R. Karnap, A. Tarskiy, R. Montegyu and others (Harker, 1990).

However, a powerful impetus given by the development of semiotics F. de Sosyur, led to the emergence not only of a new discipline (structural linguistics), but also a whole new methodological trends in science. F. de Sosyur 
singled in a natural language system in its pure form, abstracted from language development and its external relations. Structuralistic program of F. de Sosyur became the basis of numerous studies in the concrete sciences, primarily in the field of structural linguistics.

Semiotic approach has penetrated not only in linguistics but also in aesthetics, psychology, pedagogy, anthropology, cultural studies (Ziauddin, 1994). In Kazakhstan, the semiotic approach has been recognized on the comparative one. Both methods are based on the principles of a larger approach to the study of the phenomena of human culture. The most interesting results were obtained in case of a semantic method for studying the Kazakh culture.

However, it is the unity of the cultural and logical approaches suggests the possibility of a scientific foundation and integrally covers the whole complexity cultural phenomena and relationships.

The concept of "culture" refers to a number of fundamental modern social sciences. The word "culture" of Latin origin had two meanings: the action for the cultivation, processing anything, reverence, worship. However, research is often forgotten or ignored by the second meaning of culture, its second function. In our opinion, this is due to the steady trend in the medieval era dominance concept of "culture" as a "cult" in spite of the ancient Democritus' definition of culture as "second nature," by which he meant the world of human creativity.

The representatives of the Renaissance under the category of "culture" began to mean the harmonious development of human and natural or oppose its natural state of man. This tradition has strengthened further, indicating the level of human enlightenment, education and upbringing (Rojek \&Turner, 2000).

\section{Results}

In the eighteenth century there are different interpretations of background values of culture. Forerunner of a critical attitude toward culture was Jean-Jacques Rousseau, who proclaimed the idea of back to nature. In 1871 "Primitive Culture" was first viewed as signs anthropological and sociological vision of the essence of this concept: "From an ideological point of view on culture can be viewed as a general improvement of the human race by the highest individual organizations to simultaneously promote development of morality, strength, happiness of mankind"(Taylor, 1989).

In the twentieth century becomes the most traditional view of culture as a cumulative effect of human activities. Many scientists believe that the culture as a phenomenon has only been possible thanks to the ability of people to work. From this point of view, this is of interest to determine the French cultural scientist A. de Benoist, "Culture is a specificity of human activity, what characterizes man as a species. Vain search for a man to culture, its appearance on the stage of history should be considered as a cultural phenomenon. It is profoundly involves the essence of man is part of the definition of man as such (Sartre, 1996).

For the entire history of the category of "culture", in our view, is characteristic periodic return of the previous concept. Changes in attitudes towards the understanding of "culture", of course, related to the revaluation of human significance of the results of their labor. However, periodically, at times, an appeal to the interpretation of the concept of "culture" is still unmistakable. Thus, in classical antiquity definition of culture was associated with the development of the human spirit and mind. In the next era in Middle Ages it is to the fore the value of reverence, worship in a religious context. During the Renaissance it again returns to the original understanding of culture as spirituality and mind, its universality. In the Age of Enlightenment again in the culture is the main meaning of "worship, worship," but the human mind. In the XIX century it returned understanding of culture as spiritual mind as emotional culture. In XX century triumphant sense of reverence, worship honoring individuals as intelligence (Grossberg, 1992).

As you can see, through the era we observe a roll core content and direction in understanding the category of "culture." The cyclical nature of culture reflected in this most clearly.

Two meanings of culture imply two trends in the development of human culture: expanding, humanistic, democratic and concentrating, bossy, dictatorial. Human culture acted as if in two rhythms: expand and contract is keeping time with the very principle of breath (Sokal, 1996).

Thus, the whole approach to the concept of "culture" itself the meaning given to it, it becomes "magnetic needle" of the future direction of culture, its basic parameters. Culturological comprehension becomes a prognostic tool for the development of society and relationships in it, identifying its specific semantic unit. Sensual culture into the next era is replaced by rational, beyond which in turn comes again sensual. If we follow this logic change of priorities at each stage of the perception of culture, XXI century should be a century of altruistic, humanistic culture (Engel, 2008). 


\section{Discussion}

Separation of culture on two definitions of "culture" and "civilization" began in the period from 1757 to 1772 years. Urbanization and the increasing role of the material - technical culture actualized emergence of the term "civilization" as a specific form of the state of culture or particular stage of development of society (Hall et al., 1980).

In the study of the Kazakh culture it has to speak about the specifics of her approach to the analysis and evaluation. Difficulty lies in the fact that Kazakhstan is difficult definable as a nomadic culture in terms of civilization. Nomadic culture, according to many scientists, can relate in no way to civilization. Thus, Toynbee, classifying culture, consists of 26 cultures and five frozen, including nomadic calls (Griffin, 2012). Moreover, for example, N. Ya. Danilevsky subdividing civilization into three classes: Positive history makers, creators of negative stories and, finally, those peoples whose creative spirit lingered at an early stage of development, the creators of negative stories attributed not only nomads, but and Turks, Mongols, who as "God's whip" helped "give up the ghost struggling with the death of civilization". Thus, N. Ya. Danilevsky averted nomads and Turks role cleaners, orderly's civilization.

From none of these concepts cannot be fully satisfactory. You can stay at the following conclusions:

1) Kazakhstan is an independent civilization, and does not refer to any type of civilization in its purest form.

2) Kazakhstan is civilization homogeneous society. He is a special, historically a conglomerate of peoples belonging to the same type of development, combined with a strong state Turkic core.

3) Geopolitical location of Kazakhstan between the two centers of civilization influence is East and West could not affect its development: in different periods of history under the pressure that the West, the East, he had to develop the principle of alienation from both the beginning (Danilevsky, 1995).

In these three positions of Kazakhstan and Russia are very close, with the difference that the Russian civilization evolved as a heterogeneous group of Great-core. And the influence of the East and West was quite noticeable for Russia, as it is closer in different periods then to the East, then to the West. Russian influence in terms of East and West can be called "drifting society", this reflected a deep awareness of the essential it herself. Kazakhstan is "drifting" physical and household relation, and this is reflected in its principle of nomads, in his way of life (Sardar et al., 1994).

Nomadic as a second form of human existence, or not treated at all in the scientific literature, or is regarded as stiff, frozen form of culture. However, the environmental disaster that occurred in connection with the recovery from the depths of the earth lithosphere huge amounts of heavy and radioactive metals, unprecedented amounts of chemical compounds, hundreds of artificial radioisotopes, leads to self-destruction of man. Under these conditions, science thought about new forms of life on earth and remembered the first human experience is nomadic. Experience of nomadic became the object of a massive study (Gillbert, 2008).

Another feature of the Kazakh culture is that it has evolved as both nomadic and sedentary as. This was dictated by the geophysical and landscape conditions of the country. However, in essence, it is just a nomadic. All of its national identity is based on nomadic worldview. Throughout the history of its origin as a nomadic Kazakh culture has repeatedly been in mortal danger of extinction, but always survived and retained its specific features precisely because of its basis are nomads.

The history of each national culture is a process that has its own internal characteristics. Throughout the history of a particular people and its culture have common grounds on which the socio-cultural processes and developing phenomenon. Thus a common base in each national culture is a set of the most significant conditions of historical character the geopolitical position, the landscape, the biosphere and other indicators of habitat, the fundamental properties of the ethnic group and its nearest surroundings (MyFoxPhoenix.com, 2011).

These conditions form in conjunction with the presentation of historical factors on national particularity of people and its cultural and national character of its historical destiny of the national "image of the world." This creates forms of national attitude, outlook of the people that appear in mythology, folklore, custom, rituals, forms of worship, etc. For the description and comprehension of all these different, but as it turned out, closely interrelated phenomena relatively recently been introduced in the scientific revolution, the term "mentality", designed to combine the variety of meanings and values, somehow associated with the problem of national particularity. However, the concept of "mentality" wider bulkier than national identity: it is possible to identify and study of mentalities, covering and other community, in addition to the nations (religious, class, state, political, etc.). In this case, it would be correct to speak of the national mentality. 
Nomadic until the last decades of the 20th century regarded as barbarism, savagery and backwardness. He denied the existence of intellectual culture. However, it is inherent in nomadic intellectual basis. Deep structure of culture, historically and socially rooted in the minds and behavior of many generations of people, but because is basically stable mentality creates a nomadic culture as an intellectual (Toynbee, 1991).

Intelligence was the only way to survive in the conditions of nomadic. It is thanks to this quality, the way of life of the nomads was carefully detailed, so there was no need to change it, refine, as it happens in the sedentary culture. The ideal system reasonableness created conditions for instant perception of the new, its instant comprehension. It makes you think about the nomadic principle modeling systems.

Only the existence of a model could explain the tremendous power of the survival of the nomadic world and its traditions. Invented once because of its perfection did not change during the lifetime of a particular system. So, to preserve the unique form of nomadic livestock that has not changed in essence, replace only the lexical equivalent- "transhumant pastorals." That's why it was so easy again to resume the former type of management.

By definition of Nietzsche art as cultural education is a special kind of illusion: "culture is only a thin apple peel over red chaos". Nietzsche believed that art is overlooking the illusion which is best understood through the existing culture. The true source of being a nomad is hiding under art. Their life is riddled with art is the art of words, ornaments, music, design yurts, items, clothes, jewelry.

Nietzsche, giving his definition of culture, spoke about the main sense of European culture is the absolute ordering of the world according to its own laws and the substitution of authentic origins of human existence and functions of the sky God. Within this range of modern European culture is spoofed science based on the functions of the mind, intelligence, law, scientific truth, etc. And because Nietzsche, followed by the Romantics, emphasizes the role of art as an illusion, a more direct way and you know associated with life.

Of course, the formula determining Nietzsche captivating beauty, but a distraction from the civilized, modern European overtones, it is, in our opinion, very accurately describes the Kazakh culture as nomadic culture permeated by art and hides under the "thin-skinned red-hot chaos" feelings, energy sensations. Intellectual richness of the Kazakh culture recedes before domestic problems, quarrels, dissensions between relatives, between births. Although the causes of these misalignments are hidden in the very heterogeneity of tribal entities as part of the Kazakh people and are suggesting incomplete transition to the quality of the nation (Nietzsche, 1990).

\section{Conclusion}

Specificity of studying people as ethnos, its mentality is possible using various techniques. Typological, comparative and comparative approach gives excellent results in the study of national identity as a nomadic Kazakh culture compared to sedentary. Two areas of settlement surrounding Kazakhs from east and west, as would fall into the "funnel shifter" of their semantic features, especially their specificity verified encampments. Reworking the eastern mentality nomadic gives its western equivalent. Actually, East and West differ primarily antipodal their worldviews, but they are united in the person of the same quality sedentary lifestyle. Thus, a nomadic way of that line-shifter allows the existence of Eastern and Western cultures. The results of the physical disappearance of the nomadic not so strongly affect the fate of the East and West, but ambulances intellectual consequences of extinction can be very sad for the whole world culture.

Nomadic brings many challenges for researchers: independent, objective study, without "distortion" cultural factors, without enthusiasm, but at the same time without humiliation. And without the arsenal of sensory perception as nomadic Kazakh culture provides enough space for solving puzzles, their comprehension of the phenomenon (Courthouse News Service, 2012).

\section{References}

Alan, S. (1996). A Physicist Experiments with Cultural Studies (English translation of article from Lingua Franca).

Bakhtin, M. (1981). The Dialogic Imagination (p. 4). Austin, TX: UT Press.

Benoist, A. D. (1998). Favorites (p. 96).

Danilevsky, N. (1995). Russia and Europe. St. Petersburg.

Engel, M. (2008). Cultural and Literary Studies. Canadian Review of Comparative Literature, 31, 460-467.

Gilbert, J. (2008). Against the Commodification of Everything. Cultural Studies, 22(5), 551-566. http://dx.doi.org/10.1080/09502380802245811

Griffin, E. (2012). A First Look at Communication Theory (8th ed.). New York, NY: The McGraw-Hill 
Companies, Inc.

Grossberg, L., Cary, N., \& Paula, A. (1992). Treichler. Cultural Studies. New York: Routledge.

Jean-Paul, S. (1996). Words (p. 173).

Nietzsche, F. (1990). The Birth of Tragedy from the Spirit of Music.

Richard, H., Cheleen, M., \& Chris, W. (Eds). (1990). An Introduction to the Work of Pierre Bourdieu: The Theory of Practice (pp. 68-71). Houndmills: Macmillan.

Rojek, C., \& Bryan, T. (2000). Decorative sociology: Towards a critique of the cultural turn. The Sociological Review, 48(4), 629-648. http://dx.doi.org/10.1111/1467-954X.00236

Sardar, Z., \& Van, L. (1994). Introducing Cultural Studies. New York: Totem Books.

Savchenko, S. V. (2000). Culturologics problem as an academic discipline. In Almaty (p. 9).

Stuart, H., Dorothy, H., Andrew, L., \& Paul, Willis. (1980). Culture, media, language: Working papers in cultural studies, 1972-1979. London: Hutchinson.

Students Protest Ethnic Studies Curriculum Change. (2011). Retrieved April 27, 2011, from http://www.MyFoxPhoenix.com

Students, Not Teachers, Can Fight Ban on Ethnic Studies. (2012). Retrieved January 11, 2012, from http://www.Courthouse News Service

Taylor, E. (1989). Primitive Culture (p. 19). Lane.

Toynbee, A. (1991). A Study of History. Moscow.

Uzakbaeva, S. A. (1998). Concept ethno pedagogical education high school students. In Almaty (p. 11).

\section{Copyrights}

Copyright for this article is retained by the author(s), with first publication rights granted to the journal.

This is an open-access article distributed under the terms and conditions of the Creative Commons Attribution license (http://creativecommons.org/licenses/by/3.0/). 